E3S Web of Conferences 4, 03001 (2014)

DOI: $10.1051 / \mathrm{e} 3$ sconf/20140403001

(C) Owned by the authors, published by EDP Sciences, 2014

\title{
Structural and hydraulic properties of a small fault zone in a layered reservoir
}

\author{
P. Jeanne ${ }^{1,2}$, Y. Guglielmi ${ }^{2}$ and F. Cappa ${ }^{1}$ \\ ${ }^{1}$ Geoazur, University of Nice Sophia-Antipolis, Côte d'Azur Observatory, 06550 Sophia Antipolis, \\ France \\ ${ }^{2}$ CEREGE, Aix-Marseille University, 13331 Marseille, France
}

\begin{abstract}
This paper focuses on a small fault zone (too small to be detected by geophysical imaging) affecting a carbonate reservoir composed of porous and low-porous layers. In a gallery located at 250-m depth in the Underground Low Noise Laboratory, hydraulic properties of a $20-\mathrm{m}$ thick section of the reservoir affected by the studied fault are characterized by structural measurements and by a hydraulic injection in boreholes. Main result is that the damage zone displays contrasted permeability values (up to two orders of magnitude) inherited from the differential alteration of the intact rock layers. To characterize the impact of these hydraulic properties variations on the flow of fluids, numerical simulations of supercritical $\mathrm{CO}_{2}$ injections were performed with the TOUGH2 code. It appears, the permeability variations inside the fault zone favor the appearance of high fluid overpressure located in the layers having the highest permeability and storativity.
\end{abstract}

\section{Introduction}

In this paper we focus on a small fault zone. This kind of fault can play a tremendous role in loss of integrity of the reservoir-caprock systems related to the fluid pressure increase generated by a carbone dioxide $\left(\mathrm{CO}_{2}\right)$ geological storage. Fault zones can act either as barriers or conduits for fluid circulations [1]. There are strong interactions between fault zones architecture and their hydraulic properties. Faults zone are composed by a highly fractured volumes (i.e. the fault damage zones) encompassing a core zone. In the fault damage zone, the permeability is mainly governed by the fracture network. In porous formations, the deformations are mainly accommodated at the matrix scale leading to a porosity reduction [2] and by few fractures development. Inversely, in low porosity formations, fault damage zones are characterized by a high fracturing degree leading to an increase in permeability [3]. In the fault core, the permeability is influenced by the presence of fault gouges leading to a significant permeability drop. When fluids are present in fault zones, they can escape or accumulate depending on their hydraulic behavior. In this last case, the appearance of a fluid pressurization can facilitate the fault rupture. Here, we focus on small fault zone hydraulic properties affecting carbonate series. The questions that we address are: (1) how do the hydraulic properties evolve? (2) Can the fault zone architecture favor the appearance of fluids overpressure?

This is an Open Access article distributed under the terms of the Creative Commons Attribution License 4.0, which permits unrestricted use, distribution, and reproduction in any medium, provided the original work is properly cited. 


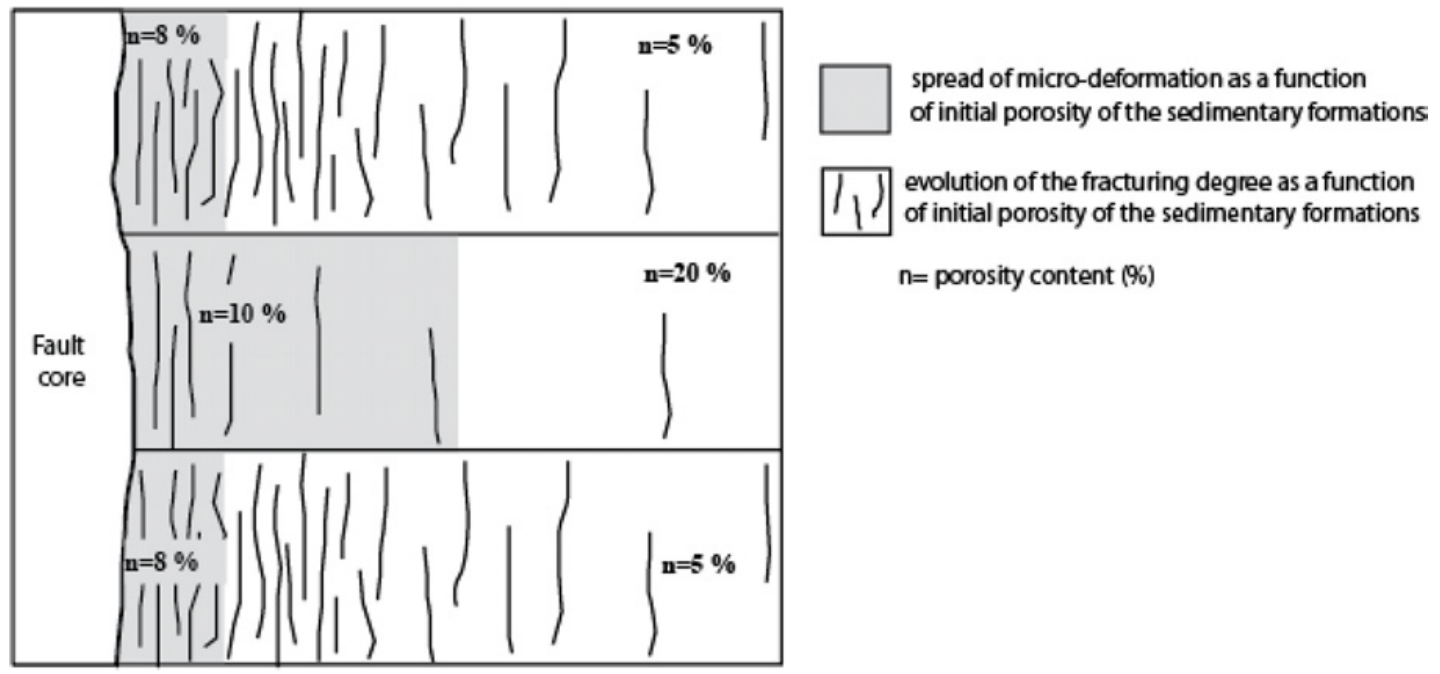

Figure 1. Conceptual model of the porosity variations along the fault zone in a carbonate reservoir.

\section{Fault zone structural properties}

We focused on a N030 fault that we investigated over a $35-\mathrm{m} \times 4-\mathrm{m} \times 26-\mathrm{m}$ volume. The explored stratigraphic sequence is composed of three mechanical units: a porous layer $(\phi=20 \%)$ with few fractures intercalated between two low-porosity highly fractured layers $(\phi=3 \%)$. In the low-porosity layers, the fracturing degree extends from the fault core over a distance of $17-\mathrm{m}$. In the porous layers, there is a rapid attenuation of the fracture porosity over a distance of 5-m related to an important accommodation of the deformations by micro-mechanisms resulting in a progressive decrease in the micro-porosity to $10 \%$. The fault core is composed of a fault gouge. From these observations, a porosity conceptual model was proposed: in low-porosity layers, the macro- and micro-fracture porosities increase toward the fault core; whereas in the porous layers, the micro-porosity decreases toward the fault core and the fracture porosity increases slightly very close to the fault core (Fig. 1).

\section{Experimental and numerical protocol}

Three wells located at different distances from the fault core to the host rock (5-m, 14-m and $18-\mathrm{m}$ relative to the main fault plane) and the "outcropping" gallery walls allow to study the evolution of the deformation of the $20-\mathrm{m}$ thick carbonate series intersected by the fault zone. The objectives were to highlight the relationships between the fault zone architecture and the hydraulic properties evolution. The hydraulic properties were evaluated with hydraulic injection tests in wells. These tests were analyzed with the numerical code TOUGH2 and compared to the rock mass properties describe by using the Q-value geological method [4]. The Q-value is defined as:

$$
Q=\frac{R Q D}{J_{n}} \times \frac{J_{r}}{J_{a}} \times \frac{J_{w}}{S R F}
$$

where $R Q D$ is the percentage of intact drill-core segments $\geq 100 \mathrm{~mm}$ in length in a selected domain (a RQD $<25 \%$ indicates very poor rock quality, 25-50\% indicates poor rock quality and 50-75\% indicates fair rock quality), $J_{n}$ is the rating for the number of joint sets ( 9 for 3 sets, 4 for 2 sets, etc.) in the same domain, $J_{r}$ is the rating for the roughness of the least favourable of these joint sets or filled 


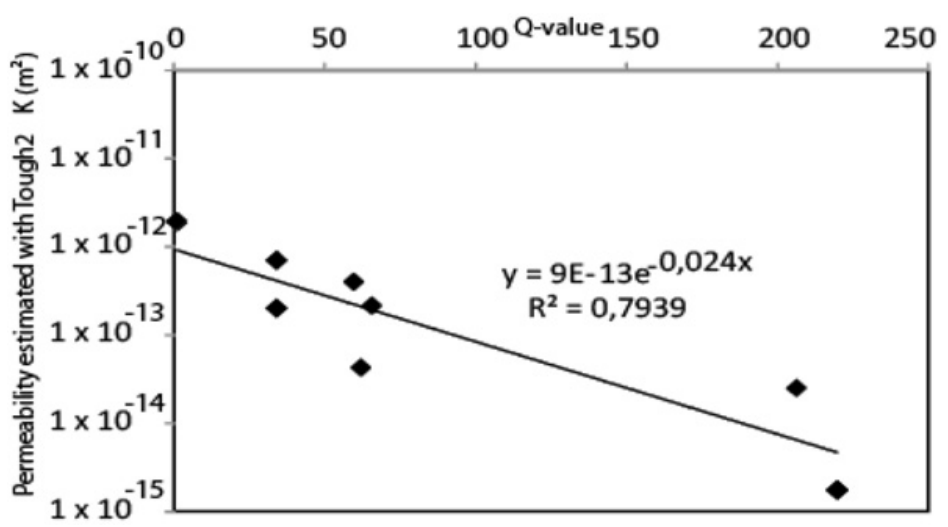

Figure 2. Correlation between Q-Value and the permeability.

discontinuities, $J_{a}$ is the rating for the degree of alteration or clay filling of the least favourable joint set or filled discontinuities, $J_{w}$ is the rating for the water inflow and pressure effects, which may cause outwash of discontinuities infillings, and SFR is the rating for the stress state.

The Q-system has been applied to more than 300 cases and it corresponds to one of the few methods to in-situ estimate fractured rock masses hydraulic parameters. Indeed, empirical correlations based on such a large number of case studies were proposed [4] between the Q-value, the rock mass strength and the Lugeon value $\left(\mathrm{L}=1 / \mathrm{min} / \mathrm{m} \approx 10^{-7} \mathrm{~m} / \mathrm{s}\right.$, which is a rough in-situ estimation of rock hydraulic permeability, Eqs. (2)-(3).

$$
\begin{aligned}
L & =1 / \mathrm{Q}_{\mathrm{c}} \\
\mathrm{Q}_{\mathrm{c}} & =\mathrm{Q} \times 100 / \sigma_{\mathrm{c}} .
\end{aligned}
$$

The uniaxial compressive strength $\sigma_{c}$ was also estimated in-situ with a Schmidt hammer. It gives a local measurement of $\sigma_{\mathrm{c}}$ for a small volume of rock from the number of rebounds (R) (Eq. (4) [6]).

$$
L \sigma_{\mathrm{c}}=2.21 \exp ^{(0.07 \times \mathrm{R})} .
$$

In this study, a measure of $\sigma_{\mathrm{c}}$ has been achieved every $10-\mathrm{cm}$ and an average $\sigma_{\mathrm{c}}$ value was established every meter and affected to the corresponding area where the $\mathrm{Q}$ factor was estimated. The $\sigma_{\mathrm{c}}$ correlates strongly with the intact rock porosity, and so it contributes to better describe the intact rock quality and the evolution of the micro-damages occurring along the fault zone.

\section{Results}

\subsection{Correlation between Q-Value and the permeability}

The plot of Q-versus-K shows a best-fitting logarithmic trend line (Fig. 2): the higher the rock quality, the lower the permeability is. Significant matrix properties variations (porosity and specific storage coefficient) were also highlighted. From this study three layers units can be distinguished:

- "Unit 1": layer of low porosity ( $\leq 9 \%$ ), low specific storage coefficient (up to $6.9 \times 10^{-3} \mathrm{~m}^{-1}$ ), low permeability (up to $1.75 \times 10^{-15} \mathrm{~m}^{2}$ ) and no fracture $\left(\mathrm{Q}_{\mathrm{c}}\right.$ up to 219 ).

- "Unit 2": layer of high porosity (20\%), high specific storage $\left(2.0 \times 10^{-2} \mathrm{~m}^{-1}\right)$, average permeability values (up to $\left.3.0 \times 10^{-13} \mathrm{~m}^{2}\right)$ and no fractures $\left(\mathrm{Q}_{\mathrm{c}}\right.$ close to 60 ). 


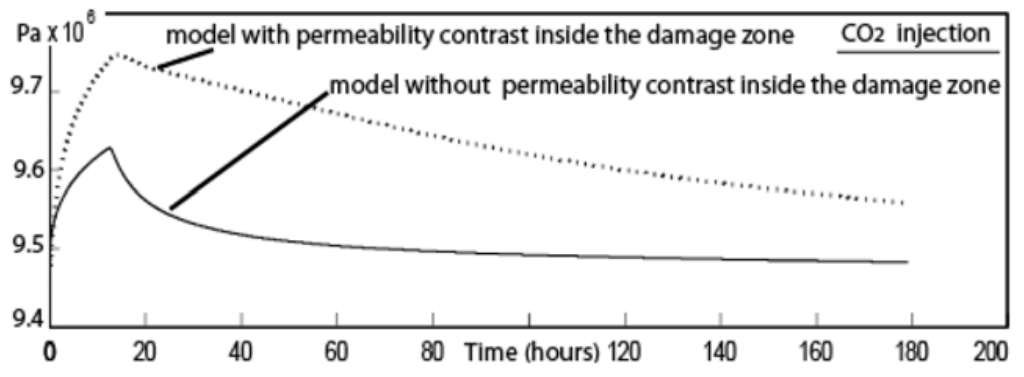

Figure 3. Fluid pressure evolution in the damage zone.

- "Unit 3": layer of low porosity (10\%), low specific storage coefficient $\left(9.8 \times 10^{-3} \mathrm{~m}^{-1}\right)$, high permeability (up to $1.8 \times 10^{-12} \mathrm{~m}^{2}$ ) and well fractured $\left(\mathrm{Q}_{\mathrm{c}}\right.$ up to 1.1 ).

Using Q-values, the permeability variations across the fault zone was estimated. Horizontal and vertical variations clearly appear showing many similarities with the conceptual porosity model. The horizontal variations are related to the fracturation degree of the layers toward the fault core. In low-porosity and fractured layers, the lowest permeability contrast between the host rock and close to the fault core is of one order of magnitude: $10^{-8} \mathrm{~m} / \mathrm{s}$ in the host rock and $10^{-7} \mathrm{~m} / \mathrm{s}$ close to the fault core. In the porous and unfractured layers, there is no significant permeability variation. Permeabilities are of $10^{-9} \mathrm{~m} / \mathrm{s}$ close to the fault core and in the host rock. In the host rock the lowest permeability contrast is of one order of magnitude between the porous and un-porous mechanical units: $10^{-9} \mathrm{~m} / \mathrm{s}$ and $10^{-8} \mathrm{~m} / \mathrm{s}$, respectively; and of two orders of magnitude close to the fault core $\left(10^{-9} \mathrm{~m} / \mathrm{s}\right.$ in the porous layer and $10^{-7} \mathrm{~m} / \mathrm{s}$ in the low-porous layers). Finally, the fault zone is characterized by strong permeable bodies more or less extended within the stratigraphic layers intercalated with low permeable bodies.

\subsection{Impact of the fault zone architecture on fluid overpressure}

To investigate the influence of the contrast of vertical and horizontal permeability inside a fault zone on the generation of fluid overpressures, we simulated a $\mathrm{CO}_{2}$ injection $(4.0 \mathrm{~L} / \mathrm{s})$ into a saline aquifer with initial conditions $\left(\mathrm{P}=9.5 \mathrm{MPa}, \mathrm{T}=32{ }^{\circ} \mathrm{C}\right.$, and a salinity of $5 \%$ by weight $)$ that assure a supercritical state for $\mathrm{CO}_{2}$. The injection point is located at $900 \mathrm{~m}$-depth in a fractured layer. The $2 \mathrm{D}$ geological model is enough large to consider infinite boundary conditions. The boundaries are impermeable.

The reservoir where is located the injection is composed by an alternation of fractured and unfractured layers of 10-m thickness. The fault damage zone is $21-\mathrm{m}$ thick in both sides of the fault core and the injection well is located in the host rock at 1-m from the damage zone. A control point is located in the damage zone at $11-\mathrm{m}$ of the injection point and 11-m of the fault core. To highlight the influence of the permeability contrasts inside a fault zone, we compare results obtained by two different models: one with contrasted permeability values inside the damage zone (Model 1) and one where permeability of the fault damage zone was considered constant and homogeneous (Model 2). The hydraulic properties and their evolution across the fault zone (permeability and storativity) used for the fluid flow simulations are deduced from the in-situ characterizations.

The permeability contrasts are present inside the damage zone (model 1) prevent the fluid diffusion and favor $\mathrm{CO}_{2}$ accumulation in the most permeable layers. Inversely, the lack of damage zone layering (model 2) favors the fluids diffusion along the fault zone and fluid overpressures in the host rock. At the end of the injection, the fluid pressures increased of $2.5 \times 10^{5} \mathrm{~Pa}$ in the damage zone in model 1 , whereas the pressure increased of to $1.2 \times 10^{5} \mathrm{~Pa}$ in model 2 (Fig. 3). In this saturated reservoir, the 
overpressures occur in high permeability and storativity layers because these layers still have the ability to store more fluids.

\section{Conclusion}

We have shown that small fault zones can strongly influence fluids circulations and storage within a reservoir. Their architectures are related to the initial stratigraphic series properties in the host rock and to their differential alteration in the damage zone. This results in the alternation of more or less permeable layers leading the appearance of levels acting as drains while others act as barriers to fluid flow. The deformations are not enough evolve to be considered as a continuous thick layer like the mature fault zone.

\section{References}

[1] Caine et al., 1996, Fault zone architecture and permeability structure. Geology 24 (11), 1025-1028.

[2] E. Tondi, 2007, Nucleation, development and petrophysical properties of faults in carbonate grainstones (Sicily, Italy). J. Str. Geo. 29, 614-628.

[3] J.E. Wilson, et al. 2003, Microfracture analysis of fault growth and wear processes, Punchbowl Fault, San Andreas System, California. J. Str. Geo. 25 (11).

[4] N. Barton, 2002, Some new Q-value correlations to assist in site characterization and tunnel design. Int. J. Rock Mech \& Mining Sc 39, 185-216.

[5] O. Katz, Z. Reches, J.-C. Roegiers, 2000, Evaluation of mechanical rock properties using a Schmidt Hammer. Int. J. Rock Mech. Min. Sci. 37, 723-728. 